\title{
A relação terapêutica sob a perspectiva analítico-comportamental
}

\author{
Robisom Carlos de Lima1 - Universidade São Francisco, Itatiba, Brasil
}

Farias, A. K. C. R. (2010). Análise comportamental clínica. Aspectos teóricos e estudos de caso. Porto Alegre: Artmed.

O livro apresentado nesta resenha tem por objetivo trazer aos leitores as características do atendimento clínico sob a perspectiva analíticocomportamental. Segundo a organizadora, não há pretensão em transformar a obra em um guia prático ou ensinar técnicas prontas para a atuação na área, mas sim proporcionar discussões acerca da postura profissional e da relação terapêutica que se estabelece entre cliente e psicólogo. O prefácio, escrito pelo professor Gilberto Godoy, trata das publicações relacionadas à análise do comportamento nas últimas décadas, ressaltando a competência e organização dos autores, que têm contribuído para o crescimento da produção e a importância de tais trabalhos para a popularização e divulgação da abordagem.

O livro, escrito em colaboração com profissionais e acadêmicos da análise do comportamento, possui 314 páginas distribuídas por 19 capítulos, divididos em duas partes. A primeira parte, denominada "Aspectos teórico-conceituais", compreende os sete primeiros capítulos e discorre sobre os aspectos teóricos relacionados à análise do comportamento, trazendo o aporte filosófico (o behaviorismo radical) e as principais teorias, relacionando-as com a prática clínica. A segunda parte, denominada "Estudo de casos", traz relatos de clínicos analítico-comportamentais acerca da prática, da relação com seus clientes e das questões levantadas pela atuação, ilustrados por detalhados estudos de caso.

No primeiro capítulo, "Por que análise comportamental clínica? Uma introdução ao livro", Farias apresenta os objetivos da obra e a importância em se observar as contingências relacionadas à relação terapêutica que se estabelece entre profissionais e clientes. Em seguida traz algumas definições e esclarece as diferenças entre a análise do comportamento e outras abordagens, como a psicologia cognitivocomportamental. A autora aproveita o espaço para desfazer algumas confusões conceituais, comuns principalmente a estudantes que não estão familiarizados com as diferenças metodológicas e as terminologias da análise do comportamento.

No capítulo seguinte, intitulado "Behaviorismo radical e prática clínica", Marçal faz uma introdução à análise do comportamento, apresentando os princípios básicos e definições relacionadas ao behaviorismo

\footnotetext{
${ }^{1}$ E-mail: robisomlima@yahoo.com.br
}

radical. O intuito do autor é facilitar o primeiro contato com a abordagem, tratando os fenômenos relacionados de forma clara, a fim de "evitar preconceitos" e diminuir as dúvidas que possam surgir entre iniciantes e profissionais de outras abordagens, além de argumentar sobre diversas críticas feitas à análise do comportamento. Por fim, Marçal propõe alguns exercícios baseados em análises funcionais de estudos de caso, destinados principalmente a iniciantes na área.

No terceiro capítulo, "Habilidades terapêuticas: é possível treiná-las?”, Abreu-Mota, Farias e Coelho tratam das características pertinentes à formação de um terapeuta analítico-comportamental e as habilidades necessárias para tal. Os autores geram uma discussão acerca da formação superior, da necessidade da supervisão clínica e sua relevância para a formação e desenvolvimento das habilidades terapêuticas. Ao final do capítulo apresentam um estudo realizado entre estudantes que cursavam disciplinas de estágios em uma universidade de Goiás e fazem uma breve discussão dos principais resultados.

Em seguida, Alves e Isidro-Marinho, no capítulo "Relação terapêutica sob a perspectiva analíticocomportamental", retomam alguns aspectos sobre o behaviorismo, traçando um breve histórico e discorrendo sobre a sua influência na psicoterapia analítico-comportamental. Em seguida, os autores discutem os procedimentos e possíveis efeitos indesejáveis sobre a relação terapêutica e o comportamento do cliente, a fim de apresentar alternativas.

No capítulo 5, intitulado "Comportamento governado por regras na clínica comportamental: algumas considerações", Medeiros trata do poder do comportamento verbal sobre as contingências às quais o cliente é exposto durante a terapia. $O$ autor argumenta sobre os prós e contras do uso das regras na intervenção, utilizando-se de diálogos extraídos de relações terapêuticas para exemplificar e ilustrar a importância do papel do cliente na formulação de suas próprias regras, a fim de diminuir a dependência deste para com o terapeuta.

No capítulo seguinte, "Autocontrole na perspectiva da análise do comportamento", Nery e Farias tratam da visão dualista mente-corpo e das implicações de tal pensamento sobre a terapia comportamental. As autoras discutem o autocontrole, contrapondo a ideia tradicional ao modelo 
externalista/interacionista da análise do comportamento, evidenciando o valor de estudos experimentais e a observação a variáveis ambientais sobre a prática clínica.

Bavin e Farias iniciam o capítulo intitulado "Análise comportamental do Transtorno de Ansiedade Generalizada (TAG)" discorrendo sobre a visão analítico-comportamental em relação aos transtornos de ansiedade, em especial ao transtorno de ansiedade generalizada. Em seguida, as autoras discutem sobre os critérios diagnósticos tradicionais, a importância da história individual do cliente para se abordar de maneira adequada o problema e a utilização de fármacos no tratamento.

Por fim, fechando a primeira parte da obra, Martins apresenta, no capítulo "Atendimento domiciliar a pacientes autistas e quadros assemelhados", a Análise do Comportamento Aplicada (ABA - Applied Behavior Analysis), técnica amplamente utilizada no tratamento do autismo, aliada ao atendimento domiciliar. $\mathrm{O}$ autor apresenta uma série de fatores sociais que justificam a utilização do tratamento domiciliar, além de apresentar dados acerca dos benefícios da utilização do $A B A$ e trazer à discussão questões referentes à atuação, à relação terapêutica com o paciente, familiares e demais profissionais em um contexto interdisciplinar.

A segunda parte da obra apresenta onze estudos de caso, a fim de ilustrar aspectos relevantes à clínica comportamental e à relação terapêutica. Em cada capítulo os colaboradores apresentam exemplos de formulações comportamentais, além de uma introdução teórica específica relacionada a cada caso clínico. No capítulo nove, Moraes discute a relevância da formulação comportamental, ilustrado por uma queixa de infelicidade e dificuldades assertivas. A seguir, Ruas, Albuquerque e Natalino tratam da correspondência entre comportamento verbal e nãoverbal. No capítulo onze, Dutra discute a relação terapêutica, apresentando conceitos da psicoterapia analítica funcional e da Teoria da Aceitação e Compromisso. A relação terapêutica também é tema da discussão de Assunção e Vanderberg, no capítulo doze. Silvia e Farias, no capítulo treze, tratam do comportamento governado por regras, enquanto os capítulos quatorze (Torres e Farias) e quinze (Fugioka e Farias) tratam de transtornos de ansiedade. No capítulo dezesseis, Nobre, Farias e Ribeiro discutem multideterminação de comportamentos observados e análises funcionais em um caso de transtorno alimentar. No capítulo dezessete, Martins Filho e Farias discutem a limitação imposta pelo atendimento de apenas um dos parceiros em um caso de transtorno sexual. No capítulo dezoito, Müller apresenta os benefícios de uma técnica focal que, quando aliada a uma visão ampla do cliente, pode se tornar importante ferramenta para a intervenção clínica. Por fim, no capítulo dezenove, Quinteiro demonstra a importância de uma intervenção global, envolvendo toda a família do cliente, através de um caso de ansiedade e medo de morte.

O livro apresenta uma linguagem clara, que reflete a preocupação dos autores em produzir uma obra acessível a estudantes e iniciantes na análise do comportamento, sem, no entanto, se tratar de uma obra introdutória. Tal preocupação pode ser observada no cuidado com a estrutura dos textos e com o aporte teórico, que é retomado e devidamente relacionado à discussão e ao tema em cada capítulo. Seguindo essa linha, a obra traz um panorama da clínica analíticocomportamental, com estudos e exemplos atuais, condizentes com a realidade $\mathrm{da}$ análise do comportamento nos dias de hoje. Apesar do universo de assuntos tratados no livro, o foco principal fica sobre a relação terapêutica, mas em momento algum a obra se assemelha a um manual técnico ou guia prático para profissionais da área. Assim, a autora apresenta um livro com uma temática robusta, expondo a vanguarda do pensamento analítico-comportamental, mas de maneira clara e assertiva, o que torna a obra imprescindível, quer para analistas do comportamento que carecem de material de qualidade, quer para profissionais de orientação comportamental, quer para iniciantes e estudantes que se interessem pelo tema.

Sobre o autor:

Robisom Carlos de Lima é acadêmico do curso de Psicologia da Universidade São Francisco. Foi bolsista de Iniciação Científica PROBAIC/USF e atualmente é bolsista PIBIC/CNPq. 